\title{
Antipsychotic Drug Use and Mortality in Older Adults with Dementia
}

Sudeep S. Gill, MD, MSc; Susan E. Bronskill, PhD; Sharon-Lise T. Normand, PhD; Geoffrey M. Anderson, MD, PhD; Kathy Sykora, MSc; Kelvin Lam, MSc; Chaim M. Bell, MD, PhD; Philip E. Lee, MD; Hadas D. Fischer, MD; Nathan Herrmann, MD; Jerry H. Gurwitz, MD; and Paula A. Rochon, MD, MPH

Background: Antipsychotic drugs are widely used to manage behavioral and psychological symptoms in dementia despite concerns about their safety.

Objective: To examine the association between treatment with antipsychotics (both conventional and atypical) and all-cause mortality.

Design: Population-based, retrospective cohort study.

Setting: Ontario, Canada.

Patients: Older adults with dementia who were followed between 1 April 1997 and 31 March 2003.

Measurements: The risk for death was determined at 30,60, 120, and 180 days after the initial dispensing of antipsychotic medication. Two pairwise comparisons were made: atypical versus no antipsychotic use and conventional versus atypical antipsychotic use. Groups were stratified by place of residence (community or long-term care). Propensity score matching was used to adjust for differences in baseline health status.

Results: A total of 27259 matched pairs were identified. New use of atypical antipsychotics was associated with a statistically signifi- cant increase in the risk for death at 30 days compared with nonuse in both the community-dwelling cohort (adjusted hazard ratio, $1.31[95 \% \mathrm{Cl}, 1.02$ to 1.70$]$; absolute risk difference, 0.2 percentage point) and the long-term care cohort (adjusted hazard ratio, $1.55[\mathrm{Cl}, 1.15$ to 2.07]; absolute risk difference, 1.2 percentage points). Excess risk seemed to persist to 180 days, but unequal rates of censoring over time may have affected these results. Relative to atypical antipsychotic use, conventional antipsychotic use was associated with a higher risk for death at all time points. Sensitivity analysis revealed that unmeasured confounders that increase the risk for death could diminish or eliminate the observed associations.

Limitations: Information on causes of death was not available. Many patients did not continue their initial treatments after 1 month of therapy. Unmeasured confounders could affect associations.

Conclusions: Atypical antipsychotic use is associated with an increased risk for death compared with nonuse among older adults with dementia. The risk for death may be greater with conventional antipsychotics than with atypical antipsychotics.

Ann Intern Med. 2007;146:775-786.

www.annals.org
$V$ arious challenging behavioral and psychological symptoms commonly develop in older adults with dementia and predispose them and their caregivers to poor outcomes (1). Nonpharmacologic strategies are recommended as first-line management for these symptoms (2), but they may be difficult to implement in clinical practice (3). For many reasons, antipsychotic medications are routinely prescribed in this setting $(4,5)$. Conventional antipsychotics, such as haloperidol, have been available since the 1950 s. Meta-analyses of clinical trials evaluating conventional antipsychotics to treat agitation in dementia show that these agents have modest efficacy and important adverse effects compared with placebo $(6,7)$. In the past decade, use of newer "atypical" antipsychotics has been rapidly increasing in clinical practice because these agents were thought to produce fewer adverse effects than conventional agents (2). A Canadian study found that the prevalence of antipsychotic use in older adults increased from $2.2 \%$ in 1993 to $3.0 \%$ at the end of 2002 . In that study, atypical antipsychotics, which were unavailable in 1993, accounted for $82.5 \%$ of all antipsychotics dispensed in 2002 (8). Short-term randomized, controlled trials (RCTs) have studied the role of atypical antipsychotics in the management of behavioral and psychological symptoms of dementia $(2,9)$. An RCT involving 421 outpatients with Alzheimer disease and psychosis, aggression, or agitation concluded that the adverse effects of these newer drugs offset their advantages (10). As a result, improvements in behavioral symptoms with antipsychotic drug treatment do not necessarily lead to improvements in overall quality of life for patients or their caregivers (11).

In April 2005, the U.S. Food and Drug Administration (FDA) issued a public health advisory that the use of atypical antipsychotics to treat elderly patients with dementia was associated with an increased risk for death compared with placebo (12). In June 2005, Health Canada issued a similar warning and additional data (13). These warnings stem from reviews of RCTs that involve the atypical agents risperidone, olanzapine, quetiapine, and aripiprazole. The mortality rate was approximately 1.6 to 1.7 times higher than with placebo and was greater with antipsychotics than with placebo in 15 of the 17 trials reviewed by the U.S. FDA (12). The warnings extend to all currently available atypical antipsychotics. Other publications have provided support for these warnings and have raised

See also:

Print

Editors' Notes . . . . . . . . . . . . . . . . . . . . . . 776

Summary for Patients. . . . . . . . . . . . . . . . . I-52

Web-Only

Conversion of figures and tables into slides 
ARTICLE $\mid$ Antipsychotic Drugs and Death among Patients with Dementia

\section{Context}

Recent reports suggest that antipsychotics are associated with increased risk for death in patients with dementia.

\section{Contribution}

This large, population-based study from Canada assessed the risk for death after dispensation of antipsychotics in older adults with dementia. New use of antipsychotics compared with nonuse was associated with increased risk for death at 30 days. Conventional agents were associated with higher risks than were atypical agents.

\section{Caution}

Sensitivity analyses showed that unmeasured confounders might diminish or erase observed associations.

\section{Implication}

Both conventional and atypical antipsychotics may be associated with an increased risk for death in elderly persons with dementia. further safety concerns about older conventional antipsychotics (14-16).

Important questions remain unanswered. Although RCTs provide the best evidence of treatment efficacy and harm, the individual RCTs in this case had low event rates. Reliable estimates of the mortality risk were generated only when data were combined by meta-analysis (14). Furthermore, these RCTs were generally short in duration and could not provide information about the long-term effect of antipsychotics on mortality $(14,17)$. Finally, these trials provide estimates of harm primarily for atypical antipsychotics. Relatively few data are available on harms associated with older conventional antipsychotics. Studies suggest that important differences may exist in the safety profiles of conventional and atypical agents $(15,16,18,19)$.

Using population-based data, we sought to determine the risk for all-cause mortality in older adults with dementia who received atypical antipsychotics, conventional antipsychotics, or no antipsychotic. Because important baseline differences exist among these groups, we used propensity score matching to improve their comparability. We also evaluated the effect of duration of treatment with antipsychotics on the risk for death.

\section{Methods}

\section{Data Sources}

Ontario is Canada's most populous province. During our study, Ontario had a population of approximately 12 million people, of whom 1.4 million were 65 years of age or older. A universally funded health program covers nearly all physician services, medications, and hospital services for patients 65 years of age or older in Ontario. Information from 4 administrative health care databases was linked to develop the study cohort: pharmacy records from the Ontario Drug Benefit program, hospitalization records from the Canadian Institute for Health Information Discharge Abstract Database, physician billing information for inpatient and outpatient services from the Ontario Health Insurance Plan, and basic demographic information and vital statistics from the Registered Persons Database. We used encrypted unique identifiers that are common among databases to link anonymous information on demographic characteristics and health services utilization for patients in our study. Little basic information on patients is missing in these databases. For example, the coding accuracy of drug claims in the Ontario Drug Benefit program database is excellent, with an error rate of only $0.7 \%(20)$.

The study was approved by the ethics review board of Sunnybrook and Women's College Health Sciences Centre, Toronto, Ontario, Canada.

\section{Dementia Cohort}

We identified a cohort of all Ontario residents 66 years of age or older with a diagnosis of dementia (in the Ontario Health Insurance Plan or Discharge Abstract Database) between 1 April 1997 and 31 March 2002. To focus on antipsychotic drug treatment for behavioral and psychological symptoms of dementia, we excluded patients who had evidence of other psychotic disorders (such as schizophrenia) or were receiving palliative care services. To reduce the potential for selection bias, we studied only new users of antipsychotics and excluded those who had received antipsychotics in the year before cohort entry (21).

\section{Exposure to Antipsychotics}

We identified new use of antipsychotics if any agent available through the Ontario Drug Benefit program was dispensed after cohort entry. Cohort entry (that is, the index date) was defined as the date of the first dispensed antipsychotic drug. Available atypical drugs included olanzapine, quetiapine, and risperidone, and available conventional drugs included chlorpromazine, flupenthixol, fluphenazine, haloperidol, loxapine, pericyazine, perphenazine, pimozide, thioridazine, and trifluoperazine. Clozapine was rarely used in Ontario during the study period, and we therefore excluded patients who were receiving this medication. Other atypical antipsychotics (such as aripiprazole and ziprasidone) are not licensed for use in Canada. We decided that exposure to an antipsychotic was discontinued (and we censored follow-up) if the patient did not refill his or her antipsychotic prescription within an interval composed of the days of drug supply plus a grace period of $20 \%$. For example, we censored follow-up for a patient who did not refill his or her 60-day antipsychotic prescription within 72 days. We also censored follow-up for patients who switched from atypical to conventional antipsychotics (or vice versa). However, we continued follow-up for patients who switched from 1 atypical antipsychotic to another, because data suggest no statistically significant dif- 
ference in the risk for death associated with individual drugs in this class $(13,14,16)$. We applied the same rules to conventional antipsychotics.

\section{All-Cause Mortality}

The primary outcome was all-cause mortality, as recorded in the Registered Persons Database (for patients who were not hospitalized at the time of death) or the Discharge Abstract Database (for patients who died while hospitalized). To assess the influence of the duration of antipsychotic exposure on the outcome, we evaluated the risk for death at 30,60,120, and 180 days after the initial dispensing of antipsychotic medication.

\section{Cohort Matching}

We stratified the dementia cohort to support separate analyses among persons living in the community and those residing in long-term care at cohort entry. Studies have demonstrated that rates of antipsychotic prescribing are substantial among older adults newly admitted to longterm care facilities (4). Furthermore, long-term care residents typically carry a greater burden of comorbid disease and are more vulnerable to adverse drug events than are their counterparts in the community $(22,23)$.

Our first objective was to determine the risk for death among older adults with dementia who received atypical antipsychotics compared with those who were not exposed to any antipsychotic. Because antipsychotic use was not randomly assigned in the study cohorts, we addressed potential confounding and selection biases by developing a propensity score for antipsychotic use. We then applied this score to match users of atypical antipsychotics with nonusers in the dementia cohort. The rationale and methods underlying the use of a propensity score for a proposed

Table 1. Characteristics of Atypical Antipsychotic Users and Nonusers

\begin{tabular}{|c|c|c|c|c|}
\hline & & \\
\hline & Atypical Antipsychotic Use & No Antipsychotic Use & Atypical Antipsychotic Use & No Antipsychotic Use \\
\hline Mean age (SD), $y$ & $81.4(6.8)$ & $81.7(7.1)$ & $85.0(7.1)$ & $85.0(7.8)$ \\
\hline Men, $n(\%)$ & $3462(38.0)$ & $3508(38.5)$ & $1132(28.0)$ & $1118(27.7)$ \\
\hline Low income status, $n(\%)$ & $3018(33.2)$ & 3033 (33.3) & $1177(29.2)$ & $1162(28.8)$ \\
\hline \multicolumn{5}{|l|}{ Medical history, $n(\%) *$} \\
\hline Myocardial infarction & $675(7.4)$ & $791(8.7)$ & $215(5.3)$ & $262(6.5)$ \\
\hline Congestive heart failure & $817(9.0)$ & $955(10.5)$ & $428(10.6)$ & $510(12.6)$ \\
\hline Peripheral vascular disease & $220(2.4)$ & $268(2.9)$ & $96(2.4)$ & $105(2.6)$ \\
\hline Cerebrovascular disease & $1047(11.5)$ & $1201(13.2)$ & $651(16.1)$ & $742(18.4)$ \\
\hline Chronic pulmonary disease & $771(8.5)$ & $877(9.6)$ & $361(8.9)$ & $409(10.1)$ \\
\hline Connective tissue disease & $93(1.0)$ & $110(1.2)$ & $41(1.0)$ & $42(1.0)$ \\
\hline Ulcer disease & $136(1.5)$ & $147(1.6)$ & $69(1.7)$ & $78(1.9)$ \\
\hline Mild liver disease & $19(0.2)$ & $20(0.2)$ & $10(0.2)$ & $9(0.2)$ \\
\hline Diabetes & $728(8.0)$ & $826(9.1)$ & $335(8.3)$ & $386(9.6)$ \\
\hline Diabetes with end-organ damage & $74(0.8)$ & $96(1.1)$ & $38(0.9)$ & $47(1.2)$ \\
\hline Hemiplegia or paraplegia & $88(1.0)$ & $101(1.1)$ & $106(2.6)$ & $126(3.1)$ \\
\hline Moderate or severe renal disease & $150(1.6)$ & $190(2.1)$ & $62(1.5)$ & $82(2.0)$ \\
\hline Primary cancer & $393(4.3)$ & $456(5.0)$ & $146(3.6)$ & $154(3.8)$ \\
\hline Moderate or severe liver disease & $13(0.1)$ & $20(0.2)$ & $6(0.1)$ & $5(0.1)$ \\
\hline Metastatic cancer & $83(0.9)$ & $101(1.1)$ & $26(0.6)$ & $34(0.8)$ \\
\hline \multicolumn{5}{|l|}{ Markers of dementia severity, $n(\%)$} \\
\hline Urinary incontinence & $681(7.5)$ & $732(8.0)$ & $242(6.0)$ & $255(6.3)$ \\
\hline Fecal incontinence & $25(0.3)$ & $31(0.3)$ & $16(0.4)$ & $19(0.5)$ \\
\hline Hospitalization with falls in the past year & $127(1.4)$ & $192(2.1)$ & $15(0.4)$ & $16(0.4)$ \\
\hline Hospitalization with delirium in the past year & $255(2.8)$ & $312(3.4)$ & $20(0.5)$ & $22(0.5)$ \\
\hline \multicolumn{5}{|l|}{ Medications, $n(\%)+$} \\
\hline Antidepressants & $2782(30.6)$ & $2788(30.6)$ & $1234(30.6)$ & $1200(29.7)$ \\
\hline Benzodiazepines & $2829(31.1)$ & $2940(32.3)$ & $1565(38.8)$ & $1537(38.1)$ \\
\hline Cholinesterase inhibitors & $1663(18.3)$ & $1494(16.4)$ & $31(0.8)$ & $22(0.5)$ \\
\hline Anticonvulsants & $273(3.0)$ & $264(2.9)$ & $259(6.4)$ & $276(6.8)$ \\
\hline \multicolumn{5}{|l|}{ Mean number of medical contacts (SD) $¥$} \\
\hline Any physician contact & $26.0(23.8)$ & $28.8(24.0)$ & $37.6(26.8)$ & $38.8(26.8)$ \\
\hline Psychiatrist & $0.6(2.6)$ & $0.5(2.6)$ & $0.2(1.0)$ & $0.2(1.3)$ \\
\hline Neurologist & $0.6(2.2)$ & $0.7(2.1)$ & $0.2(2.1)$ & $0.2(1.4)$ \\
\hline Geriatrician & $0.6(2.3)$ & $0.6(2.8)$ & $0.2(1.9)$ & $0.2(2.2)$ \\
\hline
\end{tabular}

Characteristic

Community-Dwelling Cohort (9100 Matched Pairs)

* Conditions recorded during inpatient stays in the past 5 years.

+ Medications dispensed in the 120 days before the index date.

₹ The mean number of consultations with any physician or specialists in the past year. 
ARTICLE $\mid$ Antipsychotic Drugs and Death among Patients with Dementia

Table 2. Characteristics of Conventional Antipsychotic Users and Atypical Antipsychotic Users

\begin{tabular}{|c|c|c|c|c|}
\hline \multirow[t]{2}{*}{ Characteristic } & \multicolumn{2}{|c|}{$\begin{array}{l}\text { Community-Dwelling Cohort } \\
\text { (6888 Matched Pairs) }\end{array}$} & \multicolumn{2}{|c|}{$\begin{array}{l}\text { Long-Term Care Cohort } \\
\text { (7235 Matched Pairs) }\end{array}$} \\
\hline & $\begin{array}{l}\text { Conventional } \\
\text { Antipsychotic Use }\end{array}$ & $\begin{array}{l}\text { Atypical } \\
\text { Antipsychotic Use }\end{array}$ & $\begin{array}{l}\text { Conventional } \\
\text { Antipsychotic Use }\end{array}$ & $\begin{array}{l}\text { Atypical } \\
\text { Antipsychotic Use }\end{array}$ \\
\hline Mean age (SD), $y$ & $81.8(7.0)$ & $81.8(6.9)$ & $84.2(7.1)$ & $84.3(7.0)$ \\
\hline Men, $n(\%)$ & 2740 (39.8) & $2698(39.2)$ & $2516(34.8)$ & $2423(33.5)$ \\
\hline Low income status, $n(\%)$ & $2509(36.4)$ & $2435(35.4)$ & $3114(43.0)$ & $3111(43.0)$ \\
\hline \multicolumn{5}{|l|}{ Medical history, $n(\%)^{*}$} \\
\hline Myocardial infarction & $560(8.1)$ & $575(8.3)$ & $545(7.5)$ & $590(8.2)$ \\
\hline Congestive heart failure & $744(10.8)$ & 749 (10.9) & $926(12.8)$ & $972(13.4)$ \\
\hline Peripheral vascular disease & $208(3.0)$ & $202(2.9)$ & $234(3.2)$ & $244(3.4)$ \\
\hline Cerebrovascular disease & $912(13.2)$ & $940(13.6)$ & $1387(19.2)$ & $1436(19.8)$ \\
\hline Chronic pulmonary disease & $672(9.8)$ & $681(9.9)$ & $777(10.7)$ & $847(11.7)$ \\
\hline Connective tissue disease & $72(1.0)$ & $72(1.0)$ & $86(1.2)$ & $83(1.1)$ \\
\hline Ulcer disease & $130(1.9)$ & $119(1.7)$ & $155(2.1)$ & $167(2.3)$ \\
\hline Mild liver disease & $22(0.3)$ & $19(0.3)$ & $28(0.4)$ & $24(0.3)$ \\
\hline Diabetes & $633(9.2)$ & $625(9.1)$ & $709(9.8)$ & $738(10.2)$ \\
\hline Diabetes with end-organ damage & $67(1.0)$ & $67(1.0)$ & $103(1.4)$ & $104(1.4)$ \\
\hline Hemiplegia or paraplegia & $66(1.0)$ & $77(1.1)$ & $186(2.6)$ & $204(2.8)$ \\
\hline Moderate or severe renal disease & $145(2.1)$ & $137(2.0)$ & $211(2.9)$ & $213(2.9)$ \\
\hline Primary cancer & $388(5.6)$ & $367(5.3)$ & $347(4.8)$ & $333(4.6)$ \\
\hline Moderate or severe liver disease & $16(0.2)$ & $13(0.2)$ & $16(0.2)$ & $18(0.2)$ \\
\hline Metastatic cancer & $99(1.4)$ & $80(1.2)$ & $85(1.2)$ & $78(1.1)$ \\
\hline \multicolumn{5}{|l|}{ Markers of dementia severity, $n(\%)$} \\
\hline Urinary incontinence & $442(6.4)$ & $464(6.7)$ & $508(7.0)$ & $574(7.9)$ \\
\hline Fecal incontinence & $17(0.2)$ & $20(0.3)$ & $35(0.5)$ & $48(0.7)$ \\
\hline Hospitalization with falls in the past year & $92(1.3)$ & $102(1.5)$ & $92(1.3)$ & $94(1.3)$ \\
\hline Hospitalization with delirium in the past year & $268(3.9)$ & $297(4.3)$ & $190(2.6)$ & $244(3.4)$ \\
\hline \multicolumn{5}{|l|}{ Medications, $n(\%)+$} \\
\hline Antidepressants & $1735(25.2)$ & $1856(26.9)$ & $2234(30.9)$ & $2455(33.9)$ \\
\hline Benzodiazepines & $2380(34.6)$ & $2359(34.2)$ & $3597(49.7)$ & $3594(49.7)$ \\
\hline Cholinesterase inhibitors & $254(3.7)$ & $256(3.7)$ & $132(1.8)$ & $134(1.9)$ \\
\hline Anticonvulsants & $254(3.7)$ & $241(3.5)$ & $402(5.6)$ & $399(5.5)$ \\
\hline \multicolumn{5}{|l|}{ Mean number of medical contacts (SD)‡ } \\
\hline Any physician & $27.6(26.6)$ & $28.0(25.9)$ & $42.2(31.7)$ & $43.3(30.5)$ \\
\hline Psychiatrist & $0.6(3.0)$ & $0.7(3.2)$ & $0.7(4.3)$ & $0.8(4.7)$ \\
\hline Neurologist & $0.5(2.2)$ & $0.6(2.4)$ & $0.5(2.7)$ & $0.5(3.2)$ \\
\hline Geriatrician & $0.4(2.0)$ & $0.4(1.8)$ & $0.4(3.0)$ & $0.6(3.1)$ \\
\hline
\end{tabular}

* Conditions recorded during inpatient stays in the past 5 years.

† Medications dispensed in the 120 days before the index date.

$\neq$ The mean number of consultations with any physician or specialists in the past year.

causal exposure variable are described elsewhere (24). Recent studies provide guidance on the selection of variables to include in the propensity score $(25,26)$. We developed a logistic regression model by using 42 covariates describing patient characteristics. Tables 1 and 2 list many of the characteristics included in the propensity score.

After a structured and iterative assessment of the balance of measured covariates between atypical antipsychotic users and nonusers, we applied additional forced matching to a variable indicating the presence of a hospitalization in the 90 days before cohort entry. This variable was thought to be an important predictor of new antipsychotic use and was not well balanced between groups in the propensity score. Using the resulting predicted probabilities as propensity scores, we matched each atypical antipsychotic user

$\mathbf{7 7 8}$ |5 June 2007|Annals of Internal Medicine |Volume 146 • Number 11 with a nonuser by utilizing a caliper width (that is, interval for successful match) of 0.6 of the SD of the log odds of the propensity score. This method has been demonstrated to remove approximately $90 \%$ of the bias from measured confounders (27). These steps were completed separately for each stratum (community-dwelling older adults compared with long-term care residents), resulting in 2 groups of matched pairs.

Our second objective was to determine the risk for death with conventional antipsychotic use compared with atypical antipsychotic use. We repeated the propensity score-matching process to create matched cohorts of new users of conventional and atypical antipsychotics. We stratified analyses to examine older adults residing in the community and in long-term care separately. We developed 4 
models, 1 for each of 2 drug use comparisons (atypical antipsychotic use vs. nonuse and conventional vs. atypical antipsychotic use) within each of 2 residential settings (community and long-term care).

We used a "greedy matching" algorithm (available at www2.sas.com/proceedings/sugi26/p214-26.pdf) to match new users of atypical antipsychotics to nonusers and new users of conventional antipsychotics to new users of atypical antipsychotics. Atypical antipsychotic users were eligible for both comparisons. We matched only patients with an adequate match as defined earlier and sacrificed completeness of matching for accuracy of matching.

\section{Statistical Analysis}

To examine the effects of antipsychotic use on mortality, we first examined absolute risk differences in cumulative mortality rates. We estimated $95 \%$ CIs for the absolute risk differences by using bootstrap methods with matched pairs repeated 1000 times. We then conducted survival analysis by using Cox proportional hazards models on our 4 matched cohorts. To address possible residual confounding after the matching process, we performed traditional risk adjustment with covariates that strongly influence mortality (28). The covariates in our models were age, sex, and dichotomous variables for the individual medical

\section{Figure 1. Cumulative mortality in atypical antipsychotic users and nonusers.}

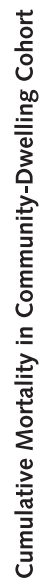

Patients at risk, $n$ Nonusers

Atypical antipsychotic users

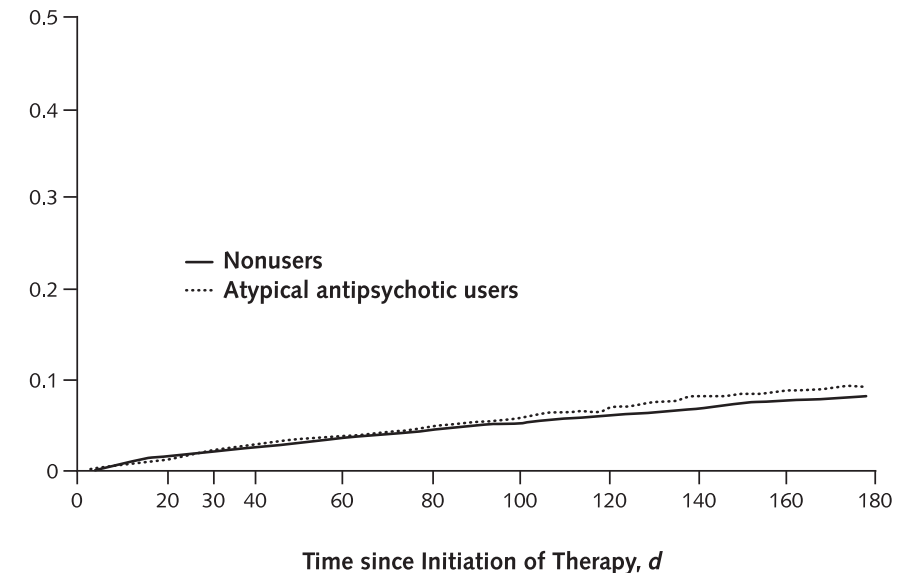

$\begin{array}{lllll}9100 & 8908 & 8762 & 8615 & 8249 \\ 9100 & 7522 & 4800 & 3591 & 1903\end{array}$

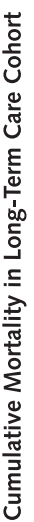

Patients at risk, $n$

Nonusers

Atypical antipsychotic

users

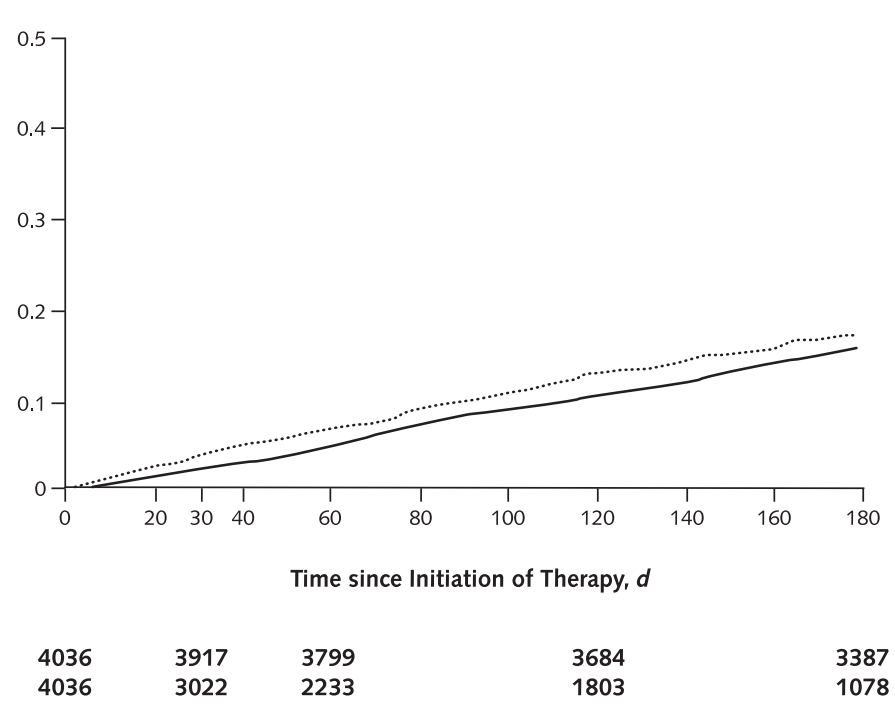


ARTICLE $\mid$ Antipsychotic Drugs and Death among Patients with Dementia

Table 3. Crude Event Rates and Absolute Risk Differences for Mortality at 30 and 180 Days

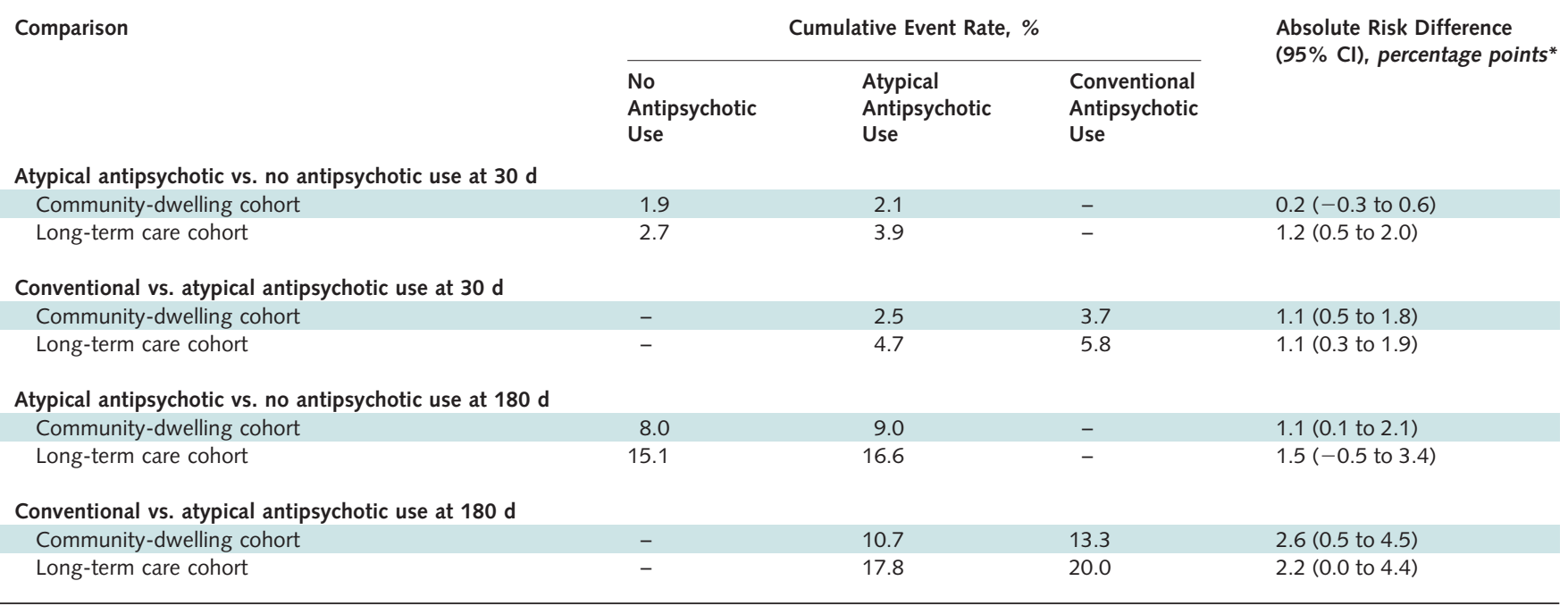

* The $95 \%$ CIs were estimated by using resampling methods (bootstrapping pairs of matched observations, with 1000 iterations).

conditions included in the Charlson comorbidity index (acute myocardial infarction, congestive heart failure, peripheral vascular disease, cerebrovascular disease, chronic pulmonary disease, connective tissue disease, ulcer disease, mild liver disease, diabetes [with and without end-organ damage], hemiplegia or paraplegia, moderate or severe renal disease, primary cancer, moderate or severe liver disease, and metastatic cancer) (29). Analyses involved stratified Cox proportional hazards models using the STRATA option of the PROC PHREG procedure in SAS, version 9.1 (SAS Institute, Inc., Cary, North Carolina), to account for the matched pair design. We ran separate models for the 30-, 60-, 120-, and 180-day end points. We confirmed the proportional hazards assumption for all models by using an interaction term between the independent variable and time. Because the $P$ value for the term was greater than 0.05 for all comparisons, we concluded that the assumption of proportional hazards was satisfied.

Although propensity score matching helps to balance groups on measured covariates, our study is observational, and unknown or unmeasured confounders may influence the results. As other investigators have done $(30,31)$, we conducted sensitivity analyses to investigate the potential effects of unmeasured confounders on the observed associations. Our sensitivity analyses investigated the effects of a hypothetical binary confounder on the observed hazard ratios for 2 comparisons in community-dwelling patients: the 30-day outcome for atypical antipsychotic use compared with no antipsychotic use, and the 30-day outcome for conventional antipsychotic use compared with atypical antipsychotic use. We varied the prevalence of the hypothetical unmeasured confounder in the 2 comparison groups, as well as the relative hazard of death associated with this unmeasured confounder.

\section{Role of the Funding Source}

The Canadian Institutes for Health Research funded the study. The funding source had no role in the design, conduct, or reporting of the study or in the decision to submit the manuscript for publication.

\section{RESULTS}

\section{Matching Process and Patient Characteristics}

For the comparison of atypical antipsychotic use with nonuse, we identified 9100 matched pairs of communitydwelling older adults and 4036 matched pairs of long-term care residents. For the comparison of conventional with atypical antipsychotic use, we identified 6888 matched pairs of community-dwelling older adults and 7235 matched pairs of long-term care residents. Thus, the study included data on 27259 propensity score-matched pairs. The matching process produced excellent balance for covariates in the propensity score (Tables 1 and 2). The standardized differences for these comparisons were nearly all less than $10 \%$. No value was missing for demographic data or data used to construct the covariates (all analysis variables were mandatory fields in our administrative databases). In the community-dwelling cohort, atypical antipsychotic users started treatment with risperidone $(75.2 \%)$, olanzapine (19.6\%), and quetiapine (5.2\%) and conventional antipsychotic users started treatment with haloperidol (60.2\%), loxapine (17.9\%), thioridazine (10.3\%), chlorpromazine $(5.8 \%)$, and perphenazine $(3.5 \%)$. The breakdown of antipsychotic use was similar in the longterm care cohort.

In all comparisons, matches were limited by the smaller of the 2 comparison groups. In the comparison of atypical antipsychotic use with nonuse, the matched pairs of community-dwelling older adults and long-term care residents repre- 
sented $96 \%$ and $48 \%$ of eligible atypical antipsychotic users, respectively. The lower match rate in the long-term care cohort reflects the smaller pool of nonusers available in this setting, because recently institutionalized people with dementia are frequently exposed to antipsychotics (4). In the comparison of conventional with atypical antipsychotic use, the matched pairs of community-dwelling older adults and longterm care residents represented $95 \%$ and $92 \%$ of eligible conventional antipsychotic users, respectively. To support the appropriateness of excluding patients for whom we could not find adequate matches, we examined the characteristics of unmatched atypical antipsychotic users. Compared with matched patients, unmatched patients were younger, were more likely to be male, were more likely to have had recent hospitalizations with delirium and investigations (such as computed tomography of the head), and had more physician and hospital visits. Those differences in the demographic profile and health services utilization of unmatched and matched atypical antipsychotic users were all statistically significant.

\section{Atypical Antipsychotic Use versus Nonuse}

Figure 1 plots cumulative mortality for atypical antipsychotic use and nonuse. Table 3 shows crude event rates and absolute risk differences for mortality at 30 and 180 days. The number of patients at risk decreased over time in an unequal manner. We were concerned that this might represent informative censoring. We therefore examined the characteristics of the remaining patients at 60 days and found that they stayed well balanced despite the unequal rates of censoring. New use of atypical antipsychotic medications was associated with a statistically significant increase in the risk for death at 30 days compared with nonuse in both the community-dwelling cohort (adjusted hazard ratio, 1.31 [95\% CI, 1.02 to 1.70$]$; absolute risk difference, 0.2 percentage point) and the long-term care cohort (adjusted hazard ratio, 1.55 [CI, 1.15 to 2.07]; absolute risk difference, 1.2 percentage points). The risk for death associated with atypical antipsychotic use persisted to
180 days in both cohorts (Tables 3 and 4). Although the hazard ratios for mortality in the long-term care cohort were similar to those in the community-dwelling cohort, cumulative mortality was almost twice as high among longterm care residents (Figure 1).

\section{Conventional versus Atypical Antipsychotic Use}

As shown in Figure 2, use of conventional antipsychotics was associated with an even greater risk for death than that observed with atypical antipsychotic use. This risk was evident at 30 days: The adjusted hazard ratio was 1.55 (CI, 1.19 to 2.02 ) for the community-dwelling cohort and 1.26 (CI, 1.04 to 1.53 ) for the long-term care cohort (adjusted risk difference for both groups, 1.1 percentage points). The risk again persisted to 180 days (adjusted hazard ratio, 1.23 [CI, 1.00 to 1.50$]$; absolute risk difference, 2.6 percentage points and 1.27 [CI, 1.09 to 1.48$]$; absolute risk difference, 2.2 percentage points, respectively) (Tables 3 and 5).

\section{Sensitivity Analyses}

Sensitivity analyses for 30-day outcomes with atypical antipsychotic use compared with nonuse found that an unmeasured confounder that increased mortality could statistically significantly diminish the observed relationship between use of atypical antipsychotics and death (Table 6). For example, if the unmeasured confounder was associated with a moderate increase in mortality (bivariate hazard ratio, 1.5), the association between atypical antipsychotic use and death was no longer statistically significant regardless of the prevalence of the unmeasured confounder in the 2 groups. On the other hand, an unmeasured confounder would need to be more strongly associated with mortality to reduce the link between conventional antipsychotic use and death at 30 days in the comparison of conventional and atypical antipsychotic use (Table 6). For example, the hazard ratio for death with conventional antipsychotic use loses statistical significance only when the unmeasured confounder has a bivariate hazard ratio of at least 2.0 and is

Table 4. Hazard Ratios ( $95 \%$ Cls) for Mortality Associated with New Use of Atypical Antipsychotics Compared with Nonuse*

Time after Initiating Therapy

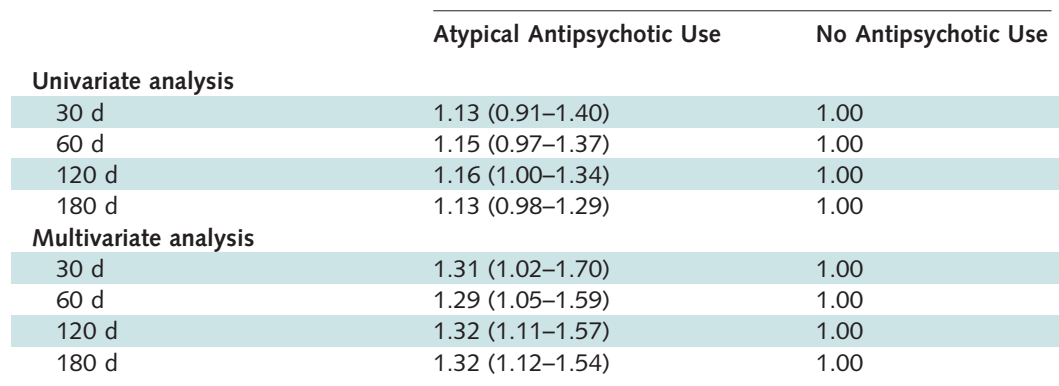

Long-Term Care Cohort (4036 Matched Pairs)

\begin{tabular}{ll}
\hline Atypical Antipsychotic Use & No Antipsychotic Use \\
& \\
$1.43(1.10-1.86)$ & 1.00 \\
$1.31(1.07-1.60)$ & 1.00 \\
$1.22(1.04-1.44)$ & 1.00 \\
$1.17(1.01-1.37)$ & 1.00 \\
& \\
$1.55(1.15-2.07)$ & 1.00 \\
$1.32(1.06-1.65)$ & 1.00 \\
$1.27(1.06-1.52)$ & 1.00 \\
$1.23(1.05-1.45)$ & 1.00
\end{tabular}

* All analyses involved stratified Cox proportional hazards models to account for the matched pair design. Univariate analyses were based on the matched cohorts without

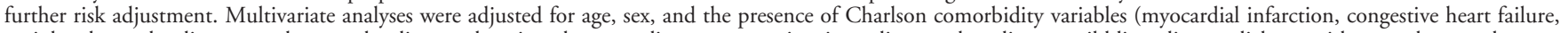

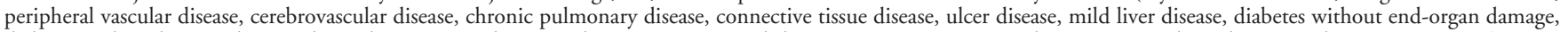
diabetes with end-organ damage, hemiplegia or paraplegia, moderate or severe renal disease, primary cancer, moderate or severe liver disease, and metastatic cancer). 
ArTiCLE $\mid$ Antipsychotic Drugs and Death among Patients with Dementia

Figure 2. Cumulative mortality in conventional antipsychotic users and atypical antipsychotic users.

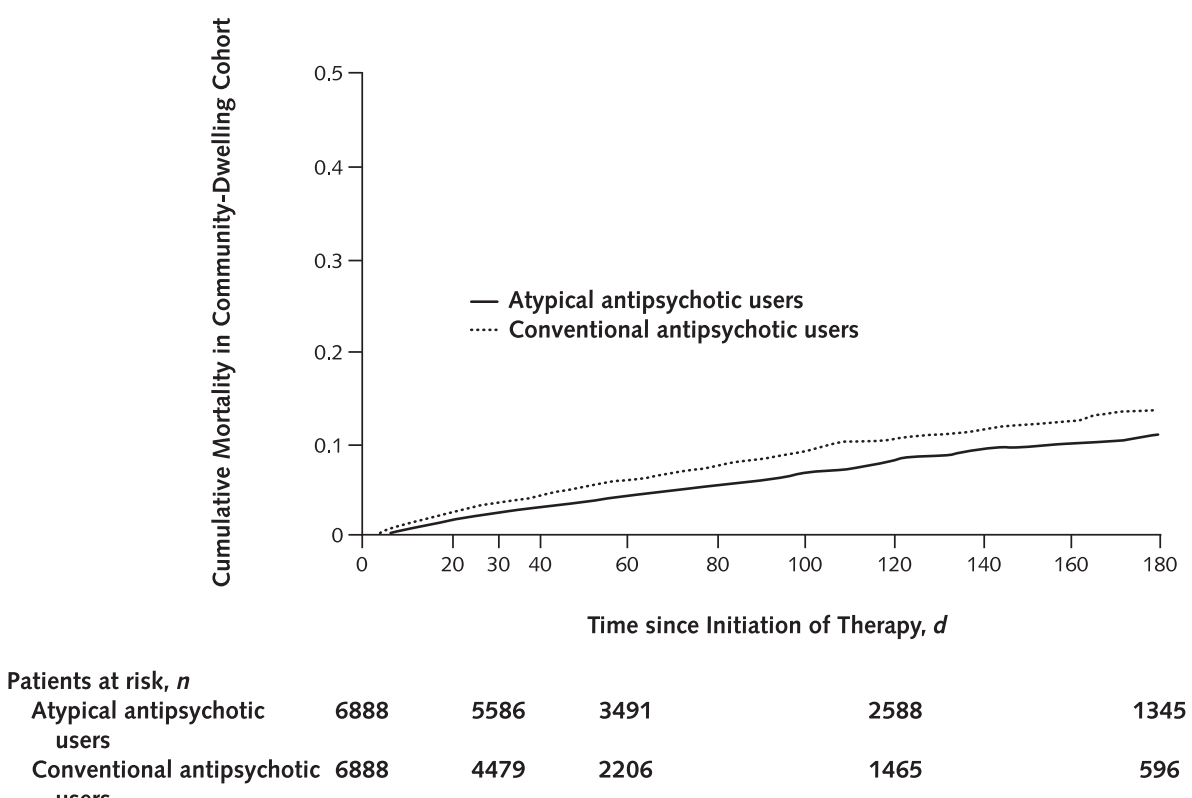

users
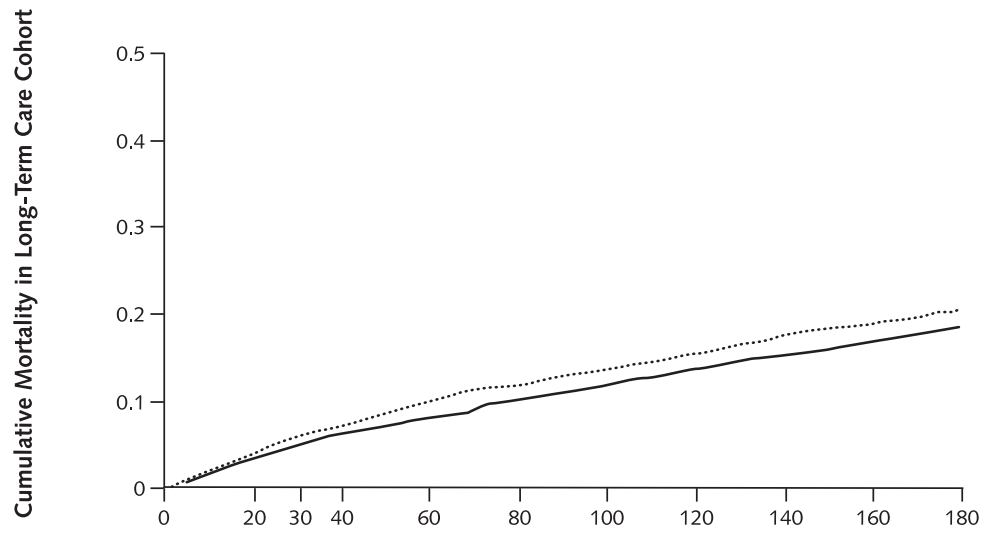

Time since Initiation of Therapy, $d$

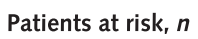

Atypical antipsychotic

7235

users

Conventional antipsychotic 7235

5327

3873

3158

1861

users

$4419 \quad 2557$

1841

932

very unevenly distributed (that is, 30\% prevalence among atypical antipsychotic users and 60\% prevalence among conventional antipsychotic users).

\section{Discussion}

Our study provides further evidence that use of atypical antipsychotics is associated with a small but significant increase in mortality among older adults with dementia. In addition, the risk for death associated with antipsychotics is apparent after as little as 1 month of use and may persist for 6 months. Finally, these data provide independent con- firmation of reports that use of conventional antipsychotics confers an even greater risk for death than does use of atypical antipsychotics $(15,18)$.

Our population-based, matched cohort study includes 5 times as many atypical antipsychotic users and nonusers as that in a meta-analysis of RCTs (14), includes many conventional antipsychotic users (a group for whom few data from RCTs exist), and provides follow-up data to 6 months. Our results complement and extend the findings of studies that examined the relationship between antipsychotic exposure and death in different patient samples 
(14-16, 18, 19, 32-37). The meta-analysis by Schneider and colleagues (14) includes 15 RCTs that evaluated several atypical antipsychotics in the short-term management of neuropsychiatric symptoms of dementia. Our results are consistent with that meta-analysis and provide further insight in a nontrial population with longer follow-up and greater exposure to conventional antipsychotics. Wang and colleagues (15) used U.S. administrative data to compare the risk for death among new users of conventional and atypical antipsychotics. They used various sophisticated observational study techniques to address potential confounding factors. Similar to our results, Wang and colleagues (15) found that conventional antipsychotics were associated with a statistically significantly higher risk for death at all intervals up to 180 days after treatment initiation. In the first 180 days of use, the absolute event rates were dramatic: $17.9 \%$ of patients who began using conventional antipsychotics and $14.6 \%$ of patients who began using atypical antipsychotics died (15).

The potential causes of death associated with antipsychotic use merit consideration. We did not have information on the proximate causes of death for all patients (38, 39). Nonetheless, several plausible mechanisms can be proposed. First, antipsychotics may prolong the QT interval, predisposing patients to arrhythmias and sudden cardiac death (40-46). Second, sedation and accelerated cognitive decline brought on by exposure to antipsychotics may increase the risk for aspiration syndromes and choking (4749). Aspiration pneumonia is an important cause of death among people with dementia (38). Third, several studies have found a link between atypical antipsychotic use and venous thromboembolism $(50,51)$; therefore, pulmonary embolism may be an underrecognized cause of sudden death in these patients. Fourth, a risk for cerebrovascular events may be associated with antipsychotic use, although this risk has been questioned $(52,53)$. Finally, antipsychotics may contribute to events that are not initially recog- nized as the first step in a sequence that promotes premature death, such as falls leading to hip fractures (54). Although details are limited, deaths in the RCTs seem to have been primarily related to cardiac arrhythmias and aspiration pneumonia (12). A review of the RCTs that evaluated olanzapine supports these proposed mechanisms of harm (16).

These results have important implications for clinical practice. First, conventional antipsychotics seem to be associated with a higher risk for death than are atypical antipsychotics $(15,18)$. Second, the estimated mortality rate among study participants was high, especially in the longterm care setting (as one might expect among vulnerable older adults with dementia) (55). Despite these high mortality rates, we can still detect excess mortality associated with exposure to antipsychotics. In the U.S. FDA and Health Canada reviews $(12,13)$, the risk for death seemed to be a class effect with all atypical antipsychotics studied, and 2 meta-analyses confirmed these findings $(14,16)$. Thus, switching between individual atypical antipsychotics in an attempt to modify the risk for death cannot be recommended. Finally, and perhaps most complex, the role of atypical antipsychotics in the management of behavioral and psychological symptoms of dementia must be carefully reviewed $(56,57)$. Rabins and Lyketsos (17) suggest an approach that limits the use of these drugs to situations in which "there is an identifiable risk of harm to the patient or others, when the distress caused by symptoms is significant, or when alternate therapies have failed and symptom relief would be beneficial." Because the risk for death associated with antipsychotics develops quickly and may persist for up to 6 months, clinicians must reevaluate benefits and risks frequently and consider discontinuation of treatment when appropriate. Studies have shown that some patients receiving antipsychotics can be successfully weaned from these medications when monitored closely $(58-61)$. Antipsychotic therapies should not be initiated if effective non-

\section{Table 5. Hazard Ratios ( $95 \%$ Cls) for Mortality Associated with New Use of Conventional Antipsychotics Compared with Atypical Antipsychotics*}

Time after Initiating Therapy Community-Dwelling Cohort (6888 Matched Pairs) $\overline{\text { Conventional Antipsychotic Use Atypical Antipsychotic Use }}$

Univariate analysis

$\begin{array}{lll}30 \mathrm{~d} & 1.43(1.15-1.78) & 1.00 \\ 60 \mathrm{~d} & 1.28(1.05-1.55) & 1.00 \\ 120 \mathrm{~d} & 1.29(1.08-1.55) & 1.00 \\ 180 \mathrm{~d} & 1.26(1.06-1.51) & 1.00 \\ \text { Multivariate analysis } & & 1.00 \\ 30 \mathrm{~d} & 1.55(1.19-2.02) & 1.00 \\ 60 \mathrm{~d} & 1.27(1.02-1.57) & 1.00 \\ 120 \mathrm{~d} & 1.26(1.02-1.54) & 1.00 \\ 180 \mathrm{~d} & 1.23(1.00-1.50) & \end{array}$

* All analyses involved stratified Cox proportional hazards models to account for the matched pair design. Univariate analyses were based on the matched cohorts without

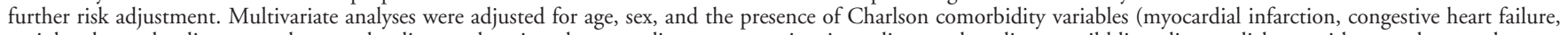

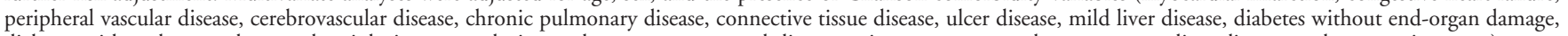
diabetes with end-organ damage, hemiplegia or paraplegia, moderate or severe renal disease, primary cancer, moderate or severe liver disease, and metastatic cancer).
Long-Term Care Cohort (7235 Matched Pairs)

Conventional Antipsychotic Use Atypical Antipsychotic Use

$\begin{array}{ll}1.34(1.12-1.59) & 1.00 \\ 1.33(1.14-1.55) & 1.00 \\ 1.32(1.14-1.52) & 1.00 \\ 1.30(1.13-1.49) & 1.00 \\ & \\ 1.26(1.04-1.53) & 1.00 \\ 1.26(1.06-1.49) & 1.00 \\ 1.26(1.08-1.47) & 1.00 \\ 1.27(1.09-1.48) & 1.00\end{array}$

5 June $2007 \mid$ Annals of Internal Medicine $\mid$ Volume $146 \bullet$ Number $11 \mid \mathbf{7 8 3}$ 
ArTiCLE $\mid$ Antipsychotic Drugs and Death among Patients with Dementia

Table 6. Representative Results from 2 Sensitivity Analyses Involving 30-Day Outcomes in the Community-Dwelling Cohorts*

Bivariate Hazard of Death†

Hazard Ratio $(95 \% \mathrm{Cl}) \mp$

\begin{tabular}{|c|c|c|c|c|}
\hline & $P_{1}=0.2 ; P_{0}=0.1$ & $P_{1}=0.4 ; P_{0}=0.2$ & $P_{1}=0.6 ; P_{0}=0.3$ & $P_{1}=0.6 ; P_{0}=0.5$ \\
\hline \multicolumn{5}{|c|}{ Analysis $1 \S$} \\
\hline 2.00 & $1.19(0.91-1.56)$ & $1.16(0.88-1.52)$ & $1.08(0.81-1.43)$ & $1.22(0.93-1.59)$ \\
\hline 1.50 & $1.24(0.95-1.62)$ & $1.22(0.93-1.60)$ & $1.21(0.91-1.60)$ & $1.26(0.97-1.64)$ \\
\hline 0.75 & $1.35(1.04-1.75)$ & $1.43(1.09-1.88)$ & $1.48(1.11-1.98)$ & $1.37(1.05-1.78)$ \\
\hline 0.50 & $1.39(1.07-1.81)$ & $1.49(1.13-1.97)$ & $1.68(1.25-2.25)$ & $1.44(1.10-1.88)$ \\
\hline \multicolumn{5}{|c|}{ Analysis 2\| } \\
\hline 2.00 & $1.37(1.04-1.80)$ & $1.35(1.02-1.79)$ & $1.21(0.89-1.63)$ & $1.43(1.10-1.88)$ \\
\hline 1.50 & $1.44(1.10-1.88)$ & $1.45(1.10-1.91)$ & $1.36(1.01-1.82)$ & $1.49(1.14-1.95)$ \\
\hline 0.75 & $1.57(1.20-2.05)$ & $1.69(1.27-2.23)$ & $1.71(1.27-2.29)$ & $1.62(1.24-2.12)$ \\
\hline 0.50 & $1.61(1.23-2.10)$ & $1.82(1.36-2.42)$ & $1.92(1.42-2.61)$ & $1.70(1.29-2.23)$ \\
\hline
\end{tabular}

* These analyses assume that the unmeasured confounder is binary, the unmeasured confounder is independent of measured confounders, there is no interaction between the

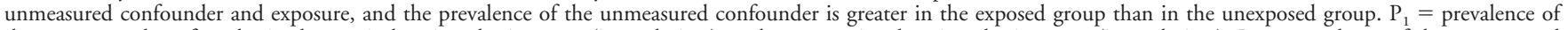

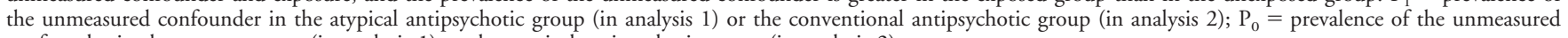
confounder in the nonuse group (in analysis 1) or the atypical antipsychotic group (in analysis 2).

† For the presence versus the absence of the unmeasured confounder (in either comparison group).

‡ For 30-day mortality.

§ Atypical antipsychotic users versus nonusers. The overall result (without adjustment for the unmeasured confounder) was a hazard ratio of 1.31 (CI, 1.02-1.70).

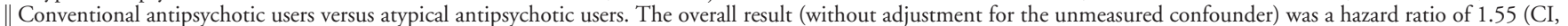
$1.19-2.02)$

drug treatments are available or if symptoms are unlikely to respond to antipsychotic treatment (for example, repetitive vocalizations or wandering). Nonpharmacologic treatments for neuropsychiatric symptoms of dementia have been reviewed (62). Clinical trials involving behavior management and caregiver education have shown benefits in both community-dwelling persons (63-65) and long-term care residents (66) and may help to minimize antipsychotic use. Efforts are needed to facilitate the implementation of these effective interventions into clinical practice (3).

Our study has important limitations. First, we used administrative data and observational study techniques. Our risk estimates are relatively small and may therefore be confounded by other variables, and our ability to control for differences in the cohorts was limited to variables with available data. The sensitivity analyses highlight these limitations. Nevertheless, our results are consistent with findings from other research, including a meta-analysis of RCTs (14). Second, we did not examine the risk for death posed by individual antipsychotic drugs. However, regulatory warnings and 2 meta-analyses have shown that the increased risk for death is consistent among the individual drugs in this class $(12-14,16)$. Third, we could not examine the causes of death. Fourth, we did not examine doseresponse relationships, given the complexity of our study design and changes in dosages over time. Of note, no statistically significant relationship between antipsychotic dose and risk for death was found in the meta-analysis of olanzapine RCTs (16). Fifth, we could not match all potentially eligible patients, which may limit the generalizability of our findings. Finally, we restricted our study to older adults with dementia. The safety of antipsychotics when used for other indications (for example, schizophrenia and delirium) requires further evaluation $(36,37,67)$.

In conclusion, we show that older adults with demen- tia who are exposed to atypical antipsychotics have a small but significant increase in overall mortality that is evident as early as 1 month after initiation of treatment, and this risk may persist for 6 months. Use of conventional antipsychotics seems to confer an even greater risk for death than does atypical antipsychotic use. These findings highlight the need to carefully balance potential risks and benefits when considering antipsychotic treatment for older adults with dementia and emphasize the need to limit use of these drugs to situations in which nonpharmacologic measures have provided an inadequate response.

From Queen's University, Kingston, Ontario, Canada; Institute for Clinical Evaluative Sciences and University of Toronto, Toronto, Ontario, Canada; Harvard Medical School and Harvard School of Public Health, Boston, Massachusetts; University of British Columbia, Vancouver, British Columbia, Canada; and Meyers Primary Care Institute of the University of Massachusetts Medical School, Fallon Clinic Foundation, and Fallon Community Health Plan, Worcester, Massachusetts.

Grant Support: By a Canadian Institutes for Health Research operating grant (no. 53124) and a Chronic Disease New Emerging Team program grant (no. 54010). The New Emerging Team program receives joint sponsorship from the Canadian Diabetes Association, the Kidney Foundation of Canada, the Heart and Stroke Foundation of Canada and the Canadian Institutes for Health Research Institutes of Nutrition, Metabolism \& Diabetes and Circulatory \& Respiratory Health. Dr. Gill is supported by an Ontario Ministry of Health and Long-Term Care Career Scientist Award. Dr. Bronskill is supported by a New Investigator Award through the New Emerging Team program. Dr. Anderson is supported by a Chair in Health Management Strategies from the University of Toronto. Dr. Rochon is supported by a Canadian Institutes for Health Research Investigator Award. Dr. Lee is supported by a fellowship grant from Eli Lilly.

Potential Financial Conflicts of Interest: Consultancies: P.E. Lee (Pfizer Canada, Janssen-Ortho), N. Herrmann (Janssen, Novartis, Pfizer Inc.); Honoraria: P.E. Lee (Pfizer Inc., Janssen-Ortho, Novartis), N. Herrmann 
(Janssen, Eli Lilly, Novartis, AstraZeneca); Expert testimony: N. Herrmann (Janssen); Grants received: P.E. Lee (Eli Lilly), N. Herrmann (Janssen).

Requests for Single Reprints: Sudeep S. Gill, MD, MSc, St. Mary's of the Lake Hospital, 340 Union Street, Kingston, Ontario K7L 5A2, Canada.

Current author addresses and author contributions are available at www .annals.org.

\section{References}

1. McKeith I, Cummings J. Behavioural changes and psychological symptoms in dementia disorders. Lancet Neurol. 2005;4:735-42. [PMID: 16239180]

2. Sink KM, Holden KF, Yaffe K. Pharmacological treatment of neuropsychiatric symptoms of dementia: a review of the evidence. JAMA. 2005;293:596-608. [PMID: 15687315]

3. Covinsky KE, Johnston CB. Envisioning better approaches for dementia care [Editorial]. Ann Intern Med. 2006;145:780-1. [PMID: 17116923]

4. Bronskill SE, Anderson GM, Sykora K, Wodchis WP, Gill S, Shulman KI, et al. Neuroleptic drug therapy in older adults newly admitted to nursing homes: incidence, dose, and specialist contact. J Am Geriatr Soc. 2004;52:749-55. [PMID: 15086656]

5. Liperoti R, Mor V, Lapane KL, Pedone C, Gambassi G, Bernabei R. The use of atypical antipsychotics in nursing homes. J Clin Psychiatry. 2003;64:1106-12. [PMID: 14628988]

6. Schneider LS, Pollock VE, Lyness SA. A metaanalysis of controlled trials of neuroleptic treatment in dementia. J Am Geriatr Soc. 1990;38:553-63. [PMID: 1970586]

7. Lanctôt KL, Best TS, Mittmann N, Liu BA, Oh PI, Einarson TR, et al. Efficacy and safety of neuroleptics in behavioral disorders associated with dementia. J Clin Psychiatry. 1998;59:550-61; quiz 562-3. [PMID: 9818639]

8. Rapoport M, Mamdani M, Shulman KI, Herrmann N, Rochon PA. Antipsychotic use in the elderly: shifting trends and increasing costs. Int J Geriatr Psychiatry. 2005;20:749-53. [PMID: 16035128]

9. Lee PE, Gill SS, Freedman M, Bronskill SE, Hillmer MP, Rochon PA. Atypical antipsychotic drugs in the treatment of behavioural and psychological symptoms of dementia: systematic review. BMJ. 2004;329:75. [PMID: 15194601]

10. Schneider LS, Tariot PN, Dagerman KS, Davis SM, Hsiao JK, Ismail MS, et al. Effectiveness of atypical antipsychotic drugs in patients with Alzheimer's disease. N Engl J Med. 2006;355:1525-38. [PMID: 17035647]

11. Ballard CG, Margallo-Lana ML. The relationship between antipsychotic treatment and quality of life for patients with dementia living in residential and nursing home care facilities. J Clin Psychiatry. 2004;65 Suppl 11:23-8. [PMID: 15264968]

12. U.S. Food and Drug Administration. FDA issues public health advisory for antipsychotic drugs used for treatment of behavioral disorders in elderly patients. FDA Talk Paper T05-13. Rockville, MD: U.S. Food and Drug Administration; 11 April 2005. Accessed at www.fda.gov/bbs/topics/ANSWERS/2005 /ANS01350.html on 9 March 2007.

13. Health Canada. Health Canada advises consumers about important safety information on atypical antipsychotic drugs and dementia. Advisory 2005-63. Ottawa: Health Canada; 15 June 2005. Accessed at www.hc-sc.gc.ca/ahc-asc/media/advisories-avis/2005/2005_63_e.html on 9 March 2007.

14. Schneider LS, Dagerman KS, Insel P. Risk of death with atypical antipsychotic drug treatment for dementia: meta-analysis of randomized placebocontrolled trials. JAMA. 2005;294:1934-43. [PMID: 16234500]

15. Wang PS, Schneeweiss S, Avorn J, Fischer MA, Mogun H, Solomon DH, et al. Risk of death in elderly users of conventional vs. atypical antipsychotic medications. N Engl J Med. 2005;353:2335-41. [PMID: 16319382]

16. Kryzhanovskaya LA, Jeste DV, Young CA, Polzer JP, Roddy TE, Jansen JF, et al. A review of treatment-emergent adverse events during olanzapine clinical trials in elderly patients with dementia. J Clin Psychiatry. 2006;67:933-45. [PMID: 16848653]

17. Rabins PV, Lyketsos CG. Antipsychotic drugs in dementia: what should be made of the risks? [Editorial]. JAMA. 2005;294:1963-5. [PMID: 16234504]
18. Nasrallah HA, White T, Nasrallah AT. Lower mortality in geriatric patients receiving risperidone and olanzapine versus haloperidol: preliminary analysis of retrospective data. Am J Geriatr Psychiatry. 2004;12:437-9. [PMID: 15249282] 19. Barnett MJ, Perry PJ, Alexander B, Kaboli PJ. Risk of mortality associated with antipsychotic and other neuropsychiatric drugs in pneumonia patients. J Clin Psychopharmacol. 2006;26:182-7. [PMID: 16633149]

20. Levy AR, O'Brien BJ, Sellors C, Grootendorst P, Willison D. Coding accuracy of administrative drug claims in the Ontario Drug Benefit database. Can J Clin Pharmacol. 2003;10:67-71. [PMID: 12879144]

21. Ray WA. Evaluating medication effects outside of clinical trials: new-user designs. Am J Epidemiol. 2003;158:915-20. [PMID: 14585769]

22. Gurwitz JH, Field TS, Judge J, Rochon P, Harrold LR, Cadoret C, et al. The incidence of adverse drug events in two large academic long-term care facilities. Am J Med. 2005;118:251-8. [PMID: 15745723]

23. Fahey T, Montgomery AA, Barnes J, Protheroe J. Quality of care for elderly residents in nursing homes and elderly people living at home: controlled observational study. BMJ. 2003;326:580. [PMID: 12637404]

24. D'Agostino RB Jr. Propensity score methods for bias reduction in the comparison of a treatment to a non-randomized control group. Stat Med. 1998;17: 2265-81. [PMID: 9802183]

25. Brookhart MA, Schneeweiss S, Rothman KJ, Glynn RJ, Avorn J, Stürmer T. Variable selection for propensity score models. Am J Epidemiol. 2006;163: 1149-56. [PMID: 16624967]

26. Austin PC, Grootendorst P, Anderson GM. A comparison of the ability of different propensity score models to balance measured variables between treated and untreated subjects: a Monte Carlo study. Stat Med. 2007;26:734-53. [PMID: 16708349]

27. Rosenbaum PR, Rubin DB. Constructing a control group using multivariate matched sampling methods that incorporate the propensity score. Am Stat 1985; 39:33-8.

28. D'Agostino RB Jr. Propensity score methods for bias reduction in the comparison of a treatment to a nonrandomized control group. In: D'Agostino RB Jr, ed. Tutorials in Biostatistics. Volume 1: Statistical Methods in Clinical Studies. New York: J Wiley; 2004.

29. Charlson ME, Pompei P, Ales KL, MacKenzie CR. A new method of classifying prognostic comorbidity in longitudinal studies: development and validation. J Chronic Dis. 1987;40:373-83. [PMID: 3558716]

30. Kern LM, Powe NR, Levine MA, Fitzpatrick AL, Harris TB, Robbins J, et al. Association between screening for osteoporosis and the incidence of hip fracture. Ann Intern Med. 2005;142:173-81. [PMID: 15684205]

31. Schneeweiss S. Sensitivity analysis and external adjustment for unmeasured confounders in epidemiologic database studies of therapeutics. Pharmacoepidemiol Drug Saf. 2006;15:291-303. [PMID: 16447304]

32. Suh GH, Shah A. Effect of antipsychotics on mortality in elderly patients with dementia: a 1-year prospective study in a nursing home. Int Psychogeriatr. 2005;17:429-41. [PMID: 16252375]

33. Scarmeas N, Brandt J, Albert M, Hadjigeorgiou G, Papadimitriou A, Dubois B, et al. Delusions and hallucinations are associated with worse outcome in Alzheimer disease. Arch Neurol. 2005;62:1601-8. [PMID: 16216946]

34. Trifirò G, Verhamme KM, Ziere G, Caputi AP, Ch Stricker BH, Sturkenboom MC. All-cause mortality associated with atypical and typical antipsychotics in demented outpatients. Pharmacoepidemiol Drug Saf. 2006. [PMID: 17036366]

35. Livingston G, Walker AE, Katona CL, Cooper C. Antipsychotics and cognitive decline in Alzheimer's disease: the LASER-Alzheimer's disease longitudinal study. J Neurol Neurosurg Psychiatry. 2007;78:25-9. [PMID: 16801350]

36. Joukamaa M, Heliövaara M, Knekt P, Aromaa A, Raitasalo R, Lehtinen V. Schizophrenia, neuroleptic medication and mortality. Br J Psychiatry. 2006;188: 122-7. [PMID: 16449697]

37. Tiihonen J, Walhbeck K, Lönnqvist J, Klaukka T, Ioannidis JP, Volavka J, et al. Effectiveness of antipsychotic treatments in a nationwide cohort of patients in community care after first hospitalisation due to schizophrenia and schizoaffective disorder: observational follow-up study. BMJ. 2006;333:224. [PMID: 16825203]

38. Keene J, Hope T, Fairburn CG, Jacoby R. Death and dementia. Int J Geriatr Psychiatry. 2001;16:969-74. [PMID: 11607941]

39. Ray WA. Observational studies of drugs and mortality. N Engl J Med. 2005;353:2319-21. [PMID: 16319379]

40. Ray WA, Meredith S, Thapa PB, Meador KG, Hall K, Murray KT. Antipsychotics and the risk of sudden cardiac death. Arch Gen Psychiatry. 2001;58: 
1161-7. [PMID: 11735845]

41. Hennessy S, Bilker WB, Knauss JS, Margolis DJ, Kimmel SE, Reynolds RF, et al. Cardiac arrest and ventricular arrhythmia in patients taking antipsychotic drugs: cohort study using administrative data. BMJ. 2002;325:1070. [PMID: 12424166]

42. Straus SM, Bleumink GS, Dieleman JP, van der Lei J, 't Jong GW, Kingma $\mathrm{JH}$, et al. Antipsychotics and the risk of sudden cardiac death. Arch Intern Med. 2004;164:1293-7. [PMID: 15226162]

43. Liperoti R, Gambassi G, Lapane KL, Chiang C, Pedone C, Mor V, et al. Conventional and atypical antipsychotics and the risk of hospitalization for ventricular arrhythmias or cardiac arrest. Arch Intern Med. 2005;165:696-701. [PMID: 15795349]

44. Straus SM, Sturkenboom MC, Bleumink GS, Dieleman JP, van der Lei J, de Graeff PA, et al. Non-cardiac QTc-prolonging drugs and the risk of sudden cardiac death. Eur Heart J. 2005;26:2007-12. [PMID: 15888497]

45. Ray WA, Meador KG. Antipsychotics and sudden death: is thioridazine the only bad actor? [Editorial]. Br J Psychiatry. 2002;180:483-4. [PMID: 12042224] 46. Hennessy S, Bilker WB, Knauss JS, Kimmel SE, Margolis DJ, Morrison MF, et al. Comparative cardiac safety of low-dose thioridazine and low-dose haloperidol. Br J Clin Pharmacol. 2004;58:81-7. [PMID: 15206997]

47. Warner J. Risk of choking in mental illness. Lancet. 2004;363:674. [PMID: 15001323]

48. Berzlanovich AM, Muhm M, Sim E, Bauer G. Foreign body asphyxiation—an autopsy study. Am J Med. 1999;107:351-5. [PMID: 10527037]

49. Ruschena D, Mullen PE, Palmer S, Burgess P, Cordner SM, Drummer $\mathrm{OH}$, et al. Choking deaths: the role of antipsychotic medication. Br J Psychiatry. 2003;183:446-50. [PMID: 14594921]

50. Zornberg GL, Jick H. Antipsychotic drug use and risk of first-time idiopathic venous thromboembolism: a case-control study. Lancet. 2000;356:1219-23. [PMID: 11072939]

51. Liperoti R, Pedone C, Lapane KL, Mor V, Bernabei R, Gambassi G. Venous thromboembolism among elderly patients treated with atypical and conventional antipsychotic agents. Arch Intern Med. 2005;165:2677-82. [PMID: 16344428]

52. Gill SS, Rochon PA, Herrmann N, Lee PE, Sykora K, Gunraj N, et al. Atypical antipsychotic drugs and risk of ischaemic stroke: population based retrospective cohort study. BMJ. 2005;330:445. [PMID: 15668211]

53. Liperoti R, Gambassi G, Lapane KL, Chiang C, Pedone C, Mor V, et al. Cerebrovascular events among elderly nursing home patients treated with conventional or atypical antipsychotics. J Clin Psychiatry. 2005;66:1090-6. [PMID: 16187764]

54. Normand SL, Sykora K, Li P, Mamdani M, Rochon PA, Anderson GM. Readers guide to critical appraisal of cohort studies: 3. Analytical strategies to reduce confounding. BMJ. 2005;330:1021-3. [PMID: 15860831]

55. Tschanz JT, Corcoran C, Skoog I, Khachaturian AS, Herrick J, Hayden
KM, et al. Dementia: the leading predictor of death in a defined elderly population: the Cache County Study. Neurology. 2004;62:1156-62. [PMID: 15079016]

56. Ballard C, Cream J. Drugs used to relieve behavioral symptoms in people with dementia or an unacceptable chemical cosh? Argument. Int Psychogeriatr. 2005;17:4-12; discussion 22-9. [PMID: 15945588]

57. Shah A, Suh GH. A case for judicious use of risperidone and olanzapine in behavioral and psychological symptoms of dementia (BPSD). Favour. Int Psychogeriatr. 2005;17:12-22. [PMID: 15945589]

58. Ray WA, Taylor JA, Meador KG, Lichtenstein MJ, Griffin MR, Fought R, et al. Reducing antipsychotic drug use in nursing homes. A controlled trial of provider education. Arch Intern Med. 1993;153:713-21. [PMID: 8447709]

59. Thapa PB, Meador KG, Gideon P, Fought RL, Ray WA. Effects of antipsychotic withdrawal in elderly nursing home residents. J Am Geriatr Soc. 1994; 42:280-6. [PMID: 7907098]

60. Meador KG, Taylor JA, Thapa PB, Fought RL, Ray WA. Predictors of antipsychotic withdrawal or dose reduction in a randomized controlled trial of provider education. J Am Geriatr Soc. 1997;45:207-10. [PMID: 9033521]

61. van Reekum R, Clarke D, Conn D, Herrmann N, Eryavec G, Cohen T, et al. A randomized, placebo-controlled trial of the discontinuation of long-term antipsychotics in dementia. Int Psychogeriatr. 2002;14:197-210. [PMID: 12243210]

62. Livingston G, Johnston K, Katona C, Paton J, Lyketsos CG; Old Age Task Force of the World Federation of Biological Psychiatry. Systematic review of psychological approaches to the management of neuropsychiatric symptoms of dementia. Am J Psychiatry. 2005;162:1996-2021. [PMID: 16263837]

63. Callahan CM, Boustani MA, Unverzagt FW, Austrom MG, Damush TM, Perkins AJ, et al. Effectiveness of collaborative care for older adults with Alzheimer disease in primary care: a randomized controlled trial. JAMA. 2006;295: 2148-57. [PMID: 16684985]

64. Vickrey BG, Mittman BS, Connor KI, Pearson ML, Della Penna RD, Ganiats TG, et al. The effect of a disease management intervention on quality and outcomes of dementia care: a randomized, controlled trial. Ann Intern Med. 2006;145:713-26. [PMID: 17116916]

65. Belle SH, Burgio L, Burns R, Coon D, Czaja SJ, Gallagher-Thompson D, et al. Enhancing the quality of life of dementia caregivers from different ethnic or racial groups: a randomized, controlled trial. Ann Intern Med. 2006;145:727-38. [PMID: 17116917]

66. Fossey J, Ballard C, Juszczak E, James I, Alder N, Jacoby R, et al. Effect of enhanced psychosocial care on antipsychotic use in nursing home residents with severe dementia: cluster randomised trial. BMJ. 2006;332:756-61. [PMID: 16543297]

67. Gill SS, Seitz D, Rochon PA. Atypical antipsychotic drugs, dementia, and risk of death [Letter]. JAMA. 2006;295:495-6 [PMID: 16449609] 


\section{Annals of Internal Medicine}

Current Author Addresses: Dr. Gill: St. Mary's of the Lake Hospital, 340 Union Street, Kingston, Ontario K7L 5A2, Canada.

Drs. Bronskill, Anderson, Bell, Fischer, and Rochon; Ms. Sykora; and Mr. Lam: Institute for Clinical Evaluative Sciences, G Wing, 2075 Bayview Avenue, Toronto, Ontario M4N 3M5, Canada.

Dr. Normand: Department of Health Care Policy, Harvard Medical School, 180 Longwood Avenue, Boston, MA 02115-5899.

Dr. Lee: St. Paul's Hospital, 1081 Burrard Street, 9th Floor, Providence Building, Vancouver, British Columbia V6T 2B5, Canada.

Dr. Herrmann: Sunnybrook Health Sciences Centre, 2075 Bayview Avenue, Toronto, Ontario M4N 3M5, Canada.

Dr. Gurwitz: Meyers Primary Care Institute, 630 Plantation Street, Worcester, MA 01605.
Author Contributions: Conception and design: S.S. Gill, S.E. Bronskill, S.-L.T. Normand, G.M. Anderson, C.M. Bell, P.E. Lee, N. Herrmann, J.H. Gurwitz, P.A. Rochon.

Analysis and interpretation of the data: S.S. Gill, S.E. Bronskill, S.-L.T. Normand, G.M. Anderson, K. Sykora, K. Lam, C.M. Bell, P.E. Lee, H.D. Fischer, N. Herrmann, J.H. Gurwitz, P.A. Rochon.

Drafting of the article: S.S. Gill, S.E. Bronskill.

Critical revision of the article for important intellectual content: S.S. Gill, S.E. Bronskill, G.M. Anderson, K. Sykora, K. Lam, C.M. Bell, P.E. Lee, H.D. Fischer, N. Herrmann, J.H. Gurwitz, P.A. Rochon.

Final approval of the article: S.S. Gill, C.M. Bell, N. Herrmann, J.H. Gurwitz, P.A. Rochon.

Statistical expertise: S.S. Gill, S.E. Bronskill, S.-L.T. Normand, K. Sykora, K. Lam.

Administrative, technical, or logistic support: K. Sykora, K. Lam, H.D. Fischer. 